\title{
Correction to: Developing real-world comparators for clinical trials in chemotherapy-refractory patients with gastric cancer or gastroesophageal junction cancer
}

\author{
Ian Chau ${ }^{1} \cdot$ Dung T. Le ${ }^{2} \cdot$ Patrick A. Ott ${ }^{3} \cdot$ Beata Korytowsky ${ }^{4}$ Hannah Le ${ }^{4} \cdot$ T. Kim Le $^{4} \cdot$ Ying Zhang ${ }^{4}$. \\ Teresa Sanchez ${ }^{4}$. Gregory A. Maglinte ${ }^{4} \cdot$ Melissa Laurie $^{4} \cdot$ Pranav Abraham $^{4} \cdot$ Dhiren Patel $^{4} \cdot$ Tong Shangguan $^{4}$
}

Published online: 3 November 2019

(c) The Author(s) 2019

\section{Correction to: Gastric Cancer https://doi.org/10.1007/s10120-019-01008-9}

The article "Developing real-world comparators for clinical trials in chemotherapy-refractory patients with gastric cancer or gastroesophageal junction cancer", written by Ian Chau, Dung T. Le, Patrick A. Ott, Beata Korytowsky, Hannah Le, T. Kim Le, Ying Zhang, Teresa Sanchez, Gregory A. Maglinte, Melissa Laurie, Pranav Abraham, Dhiren Patel, Tong Shangguan, was originally published electronically on the publisher's internet portal on 23 September 2019 without open access. With the author(s)' decision to opt for Open Choice the copyright of the article changed on 25 October 2019 to $\odot$ The Author(s) 2019 and the article is forthwith distributed under a Creative Commons Attribution 4.0 International License (https://creativecommons.org/licenses/ by/4.0/), which permits use, sharing, adaptation, distribution and reproduction in any medium or format, as long as you give appropriate credit to the original author(s) and the source, provide a link to the Creative Commons licence, and indicate if changes were made.

The original article has been corrected.

Open Access This article is distributed under the terms of the Creative Commons Attribution 4.0 International License (http://creativecommons.org/licenses/by/4.0/), which permits unrestricted use, distribution, and reproduction in any medium, provided you give appropriate credit to the original author(s) and the source, provide a link to the Creative Commons license, and indicate if changes were made.

Publisher's Note Springer Nature remains neutral with regard to jurisdictional claims in published maps and institutional affiliations.

The original article can be found online at https://doi.org/10.1007/ s10120-019-01008-9.

Ian Chau

Ian.Chau@rmh.nhs.uk

1 Gastrointestinal and Lymphoma Unit, The Royal Marsden Hospital, Surrey SM2 5PT, UK

2 Sidney Kimmel Comprehensive Cancer Center At Johns Hopkins, Baltimore, MD, USA

3 Dana-Farber Cancer Institute, Boston, MA, USA

4 Bristol-Myers Squibb Company, Lawrenceville, NJ, USA 